\title{
https://doi.org/10.46813/2021-133-136 \\ IMPROVED FAST PROTECTION SYSTEM AT HIGH-VOLTAGE GAS BREAKDOWNS FOR INDUSTRIAL ELECTRON ACCELERATORS
}

\author{
S.O. Bandurov ${ }^{1}$, R.S. Lozhkin', G.O. Shyshkin ${ }^{3}$ \\ 1 “Azov Cable Company” LLC, Berdyansk, Ukraine \\ E-mail: science.azovcablecompany@gmail.com; \\ ${ }^{2}$ National Technical University "Kharkiv Polytechnic Institute”, Kharkiv, Ukraine \\ E-mail: rslozhkin@gmail.com; \\ ${ }^{3}$ Berdyansk State Pedagogical University, Berdyansk, Ukraine \\ E-mail: ur3qugs@gmail.com
}

The article considers the ways to improve the protection system of linear electron accelerators ELV-1 and ELV-2 series on the basis of modern integrated and semiconductor component base. The proposed circuit solutions allowed turning off the facility power in case of gas electrical insulation breakdowns in the fast mode, that makes it impossible to work in an emergency. In order to improve the quality of control over the accelerator operation and additional informing an operator, capability of the proposed system to display information on the operator's computer monitor has been realized.

PACS: 29.20.-c. 41.75.Fr

\section{INTRODUCTION}

The most common type of industrial electron accelerators for various products radiation treatment are linear electron accelerators of ELV type [1,2]. Due to successful technical solutions, that have ensured their highquality characteristics, the operation some of the first in its model range of electron accelerators series ELV-1 and ELV-2 are no less important so far. The accelerators of this series gained special demand at enterprises producing cable-conductor products as a source of ionizing radiation for radiation modification of polymer insulation and cable products sheath. This modification method made it possible to increase mechanical strength and chemical resistance of polymer insulation, improve electrical insulation characteristics and increase its heat resistance, which promotes to expand the possibility of using cables and wires. The involvement of radiation technologies on the accelerator data basis made it possible to process not only insulating polymers of cable-conductor products, but also cable protective elements, which are compressed under the influence of temperature: heat shrink sleeves, heat-shrink end plugs, and the like. In turn, this allowed expanding the range of products manufactured by enterprises.

The accelerators of the presented series consist of a high-voltage accelerating voltage generator, an accelerating tube, a gas and vacuum system, and an electron beam outlet system.

The generator and the accelerating tube are located in the vessel, which is filled pressurized with SF6 gas, that provides gas electrical isolation. The accelerating tube is built into the column, which passes through the rectifying sections (Fig. 1,a). In the lower part, it ends with a neck, which passes through the vessel bottom and is attached to a vacuum system, consisting of two magnetically and discharge diode pumps of the NORD-250 type.

A Pierce gun with a perveance $P \approx 0.4 \cdot 10^{-6} \mathrm{~A} / \mathrm{V}^{3 / 2}$ has been installed on the upper flange of the accelerating tube [3]. A lanthanum hexaboride pellet $\left(\mathrm{LaB}_{6}\right)$ with indirect heating from a separate power supply with a power of at least $50 \mathrm{~W}$ has been used as an electron source. In ELV-1 and ELV-2 series electron accelerators, the voltage at the first anode $\mathrm{Ua}$ is set by a separate power supply in the range $0 \ldots 4 \mathrm{kV}$, that allows controlling the value of the beam current injected by the cathode into the accelerating channel. At the exit of the accelerating channel, an electron beam with a diameter of $\approx 10 \mathrm{~mm}$ enters a magnetic field formed by the deflection system coils and unfolds in two mutually perpendicular directions on a titanium foil $50 \mu \mathrm{m}$ thick with an outlet window size of $75 \times 980 \mathrm{~mm}$. A voltage divider is used to uniformly distribute the accelerating voltage across the gradient electrodes (see Fig. 1,a).

A step-up transformer with primary and secondary windings is used as an accelerating voltage high-voltage generator. The primary winding shown in Fig. 1,b consists of a fiberglass end-frame wounded with thirty turns of a doubled copper tube with a diameter of $12 \mathrm{~mm}$ and a wall thickness of $1 \mathrm{~mm}$. Cooled demineralized water (refrigerant) is pumped through the tubes.

The secondary winding has a sectional design. Each section has its own coil with the number of turns $W_{2}=3130$ and its own rectifier, which has been assembled according to the doubling circuit (see Fig. 1,a). The alternating voltage, which is induced on the sections' coils, is converted into a constant voltage by a twostroke rectifier circuit. The rectifiers are connected in series, forming a chain of rectifier sections, with a total of 24 for ELV-1 accelerators and 37 for ELV-2 accelerators, which ends with a hemispherical electrode, which is under high potential.

Thus, the accelerating voltage high-voltage generator is a step-up transformer, which allows obtaining the electron beam energy in the range of $0.4 \ldots 0.8 \mathrm{MeV}$ for ELV-1 at a beam current of $40 \mathrm{~mA}$ and $0.8 \ldots 1.5 \mathrm{MeV}$ for ELV-2 at a beam current of $25 \mathrm{~mA}$. When accelerating voltages are generated in the above range, it is necessary to pay attention to the protection of the high voltage generator from various possible emergencies. 
In this connection, there is a need to develop new protection systems for ELV-1 and ELV-2 series accelerators. Such systems must shut down the accelerator in as short time as possible in order to better protect the high-voltage rectifier and the secondary winding of the step-up transformer from damage. To solve this problem, it is necessary to improve existing fast protection systems in case of high-voltage breakdowns.

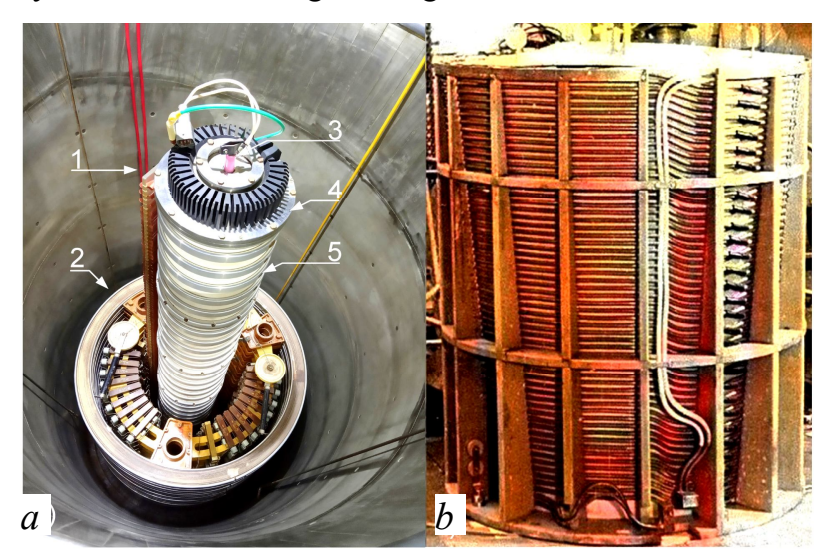

Fig. 1. High-voltage generator (inner part of the vessel):

1 - accelerating voltage divider; 2 - rectifying section;

3 -Pierce gun; 4 -accelerating tube; 5 -gradient electrodes (a). Frame and primary winding of the step-up transformer (b)

The analysis of scientific and technical literature and dissertations in recent years has shown that the problems of automation, protection, in particular, the improvement of fast protection systems at high-voltage breakdowns of accelerators series ELV-1, ELV-2 were given insufficient attention. It didn't allow completely revealing their technical potential, extend service life and fully meet the requirements of modern production. It is these factors that actualize the topic of this study.

\section{PROBLEM FORMULATION}

During the accelerators ELV-1 and ELV-2 series operation the cases of the gas electrical insulation highvoltage breakdown may be occurred. It should be noted that the probability of such a phenomenon is extremely small, but it takes the place in practice. The breakdown cause may be, in particular, insufficient amount of insulating gas $\left(\mathrm{SF}_{6}\right)$ or its low quality, and so on. In [4], the processes that occur at the breakdown of gas electrical insulation on the high side (by high side we mean a high-voltage rectifier) are described in sufficient detail. The authors emphasized that the power supplies of ELV-type accelerators must withstand this kind of breakdowns.

The standard "Protection block", which includes the fast protection scheme, is provided for additional protection of the high-voltage generator at possible highvoltage breakdowns of electric gas isolation as a part of accelerators ELV type. The accelerators manufacturer emphasizes that the fast protection system during time $\tau \approx 1 / 2$ period of the transformer primary winding supply voltage change allows you to turn off the accelerator in case of an alarm signal in the occurrence of highvoltage breakdowns. The electric circuit diagram of the fast protection system at high voltage breakdowns is shown in Fig. 2.
The fast protection circuit at the high-voltage breakdown of gas electric isolation has two inputs: "input +" and "input -". The principle of the above circuit operation is as follows: in the event of a breakdown, the current pulse comes from the terminal "beam current" to the input of the protection circuit "input +". Part of this current through R4, R12, and VD3 enters the control thyristor T2, which being opened, causes the accelerator to turn off. The circuit sensitivity is set by the variable resistor R2 "average current level". The second input "input -“, according to the developers' recommendations, can be fed from the doubling circuit capacitive divider, which is installed on the rectifier section (Fig. 1,b). A resistor R6 allows you to set the desired level of the circuit operation. This input is more sensitive, as the "jump" of current from the input is amplified by a cascade assembled on the transistor VT1 (the input stage under normal conditions is open).

The fast protection circuit works as follows: at breakdowns on the "high side" the transistor VT1 is closed, current redistribution appears, that causes opening of the thyristor T2. The failure of the blocking generator, which controls the thyristor key, occurs. The power supply of the rectifier is stopped by disconnecting the transformer primary winding (see Fig. 1,b) with a thyristor key. When the blocking generator fails, the electromagnetic relay $\mathrm{K} 1$ is triggered, which turns off the power to the starter winding P1, which in turn is designed to further disconnect the accelerator primary winding. As can be seen from the scheme in Fig. 2, the blocking generator consists of the transistor VT2 and the capacitor $\mathrm{C} 8$, which together form periodic oscillations in the windings of the pulse transformer T1 with a frequency of $10 \ldots 15 \mathrm{kHz}$. According to the scheme (see Fig. 2), the sweep unit is connected to the fast protection system. If an emergency occurs in the line coils of the electron beam deflection in the event of an emergency, the blocking generator generation will be disrupted and the power supply to the accelerator will stop. The occurrence of emergency situations is signaled by the emergency light La1, which indicates thyristor switch shutdown. The SB1 button is used to check the thyristor key shutdown. The SB2 button is designed to resume blocking generator frequency generation.

Structurally, this scheme, despite its technical simplicity and reliability, has disadvantages, namely: large dimensions due to the use of a pulse transformer $\mathrm{T} 1$ type $\mathrm{G} \times 4.720 .028$ (see Fig. 2), which is used to operate the blocking generator; the use of voltages of different magnitude and polarity for the power supply circuit, namely: $\pm 9,35 \mathrm{~V}$, requires the applying of a power transformer with a larger number of windings, that significantly increases its size.

In order to eliminate the above circuit shortcomings and increase the level of the high-voltage rectifier protection during the breakdown of gas electrical insulation of electron accelerators ELV-1 and ELV-2, we worked to improve the electrical circuit (see Fig. 2). To reduce the scheme dimensions and improve its quality characteristics, we have done:

1. The pulse power supply unit for $15 \mathrm{~V}, 50 \mathrm{~W}$ and the integrated stabilizer VR1 for $12 \mathrm{~V}$ (Fig. 3) are included in the circuit, that promoted to reduce the trans- 
former size of the power circuit and allowed us to supply circuit components with a voltage of the same magnitude and polarity.

2. The blocking generator based on the transformer T1, which has a permalloy core, the transistor VT2 and the capacitor C8, has been removed (see Fig. 2). The blocking generator has been substituted a different circuit of the relaxation generator on the "Gen1" integrated circuit, which operates in the astable mode. The field-effect transistor T3 and a transformer on the smaller ferrite core Tr1 are connected to the generator (see Fig. 3). In turn, this allowed getting a more stable signal generation circuit on the integrated circuit NE555N, with voltage drift $-0.1 \% / \mathrm{V}$ and temperature drift $-0.005 \% /{ }^{\circ} \mathrm{C}$ (see Fig. 3).

3. The breakdown sensor is assembled on the bipolar transistor VT1, which amplifies the signal, and on the trigger IC1 (see Fig. 3) with an input current of not more than $0.3 \mu \mathrm{A}$, that allowed obtaining a more sensitive input than the input "input + ", a signal from which comes to the thyristor T2 with an input current of $250 \mathrm{~mA}$ (see Fig. 2).

4. Since the optical elements are less sensitive to external electromagnetic radiation, the thyristor T2 (see Fig. 2) was substituted for the optical pair IC3 (see Fig. 3). This ensured better circuit operation.

The above improvements formed the basis of the new protection system scheme developed by us (see Fig. 3), for which a utility model patent of Ukraine has been obtained [5].

\section{SCHEME OPERATION CONCEPT AND EXPERIMENTAL PART}

In Fig. 3 it is shown the improved scheme of the accelerators fast protection system at high-voltage breakdowns of gas insulation developed by us. This scheme is simplified and does not claim to be complete and is given to explain the operation of its elements. Consider the principle of its operation: in the event of a highvoltage breakdown of gas electrical insulation, the pulse on the high-voltage rectifier, formed from the circuit C5, R16 is arrived to the terminal X1 of the arrester F1. Then it passes through the second differential circuit, consisting of the capacitors $\mathrm{C} 1-\mathrm{C} 3$ and the resistors R1, $\mathrm{R} 2$. The rest of the signal is arrived to the variable resistor R3 "the circuit sensitivity setting". This resistor sets the value of the protection response level, followed by the signal through the limiting resistor R5 enters the base of the transistor VT1 series BC550C, thereby opening it. The control pulse is taken directly from the transistor VT1 emitter and arrived to the input (6 output) of the trigger IC1 on the chip CD4013. The transistor VT1 and the chip IC1 form a breakdown sensor. When the driving pulse is arrived to the chip input (6 output) IC1, the trigger enters a steady, operating state, and at its outlet ( 1 output) there is a logic value " 1 ", which is equivalent to a voltage of $12 \mathrm{~V}$. When the pulse at the chip input is missing, a logical value " 0 ", which is equivalent to a voltage of $0 \mathrm{~V}$ will be at its outlet (1 output).

Accordingly, when the trigger IC1 is in the operating state, the voltage from its output through the buffer resistor R10 is fed to the base of the bipolar transistor VT2. The transistor is opened, that leads to the electromagnetic relay Rel1 triggering and turning on the LED HL1. Outputs 2, 3 of the relay Rel1 mechanical contacts are connected to the control circuit by the starter winding P1, which interrupts the power supply to the frequency converter FC. The LED NL1 notifies the operator of the high-voltage breakdown presence and signal generation failure, which is arrived to the control terminals of the thyristor switch T1, T2. In this case, the electromagnetic relay Rel1 is used as a controlling element of the accelerator disabling.

The optical pair IC3 is connected to the output 2 of the IC1 chip, which interrupts the generation of rectangular pulses with a frequency of $20 \mathrm{kHz}$ of the "Gen 1" generator assembled on the NE555N chip.

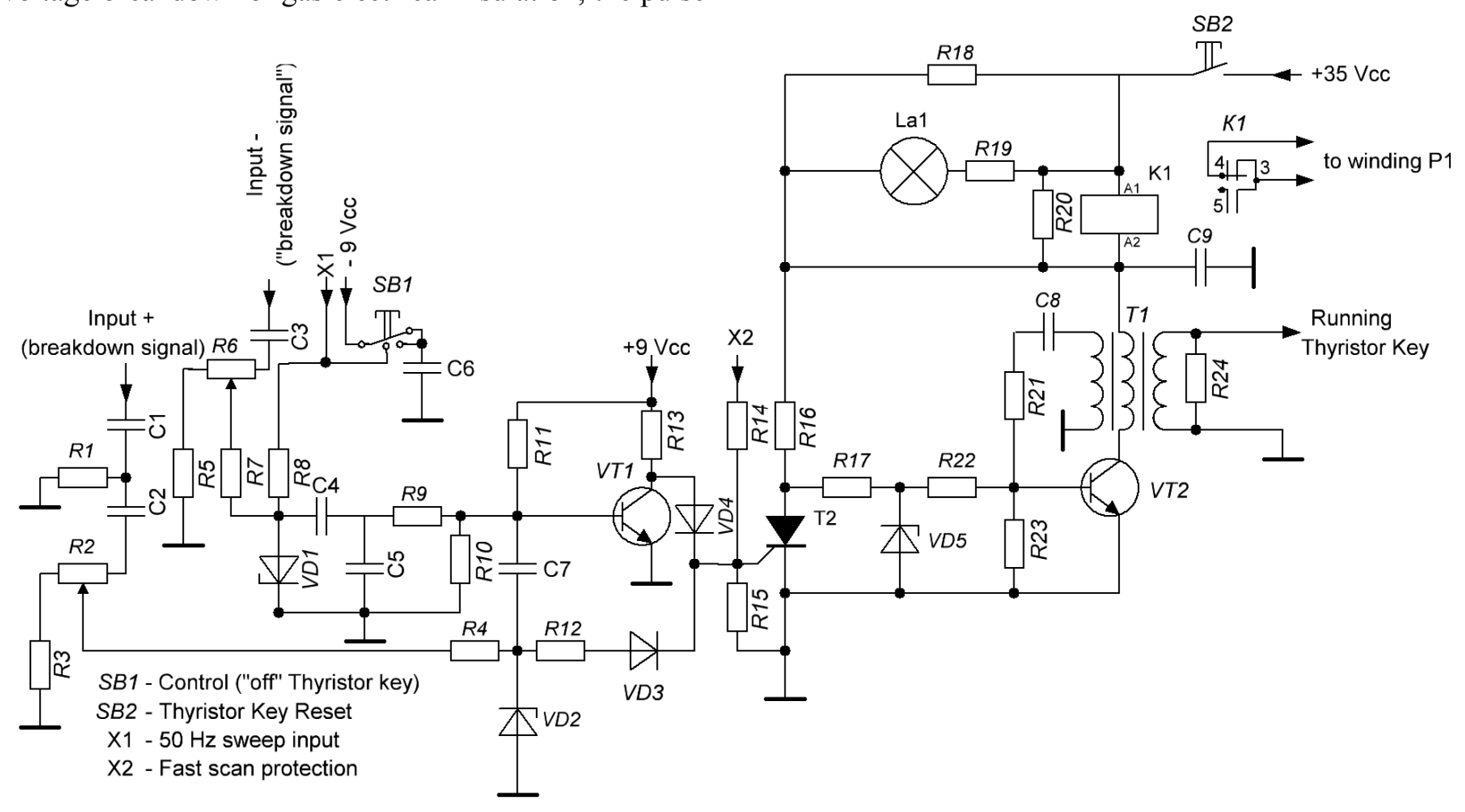

Fig. 2. Standard schematic circuit diagram of the fast protection unit 


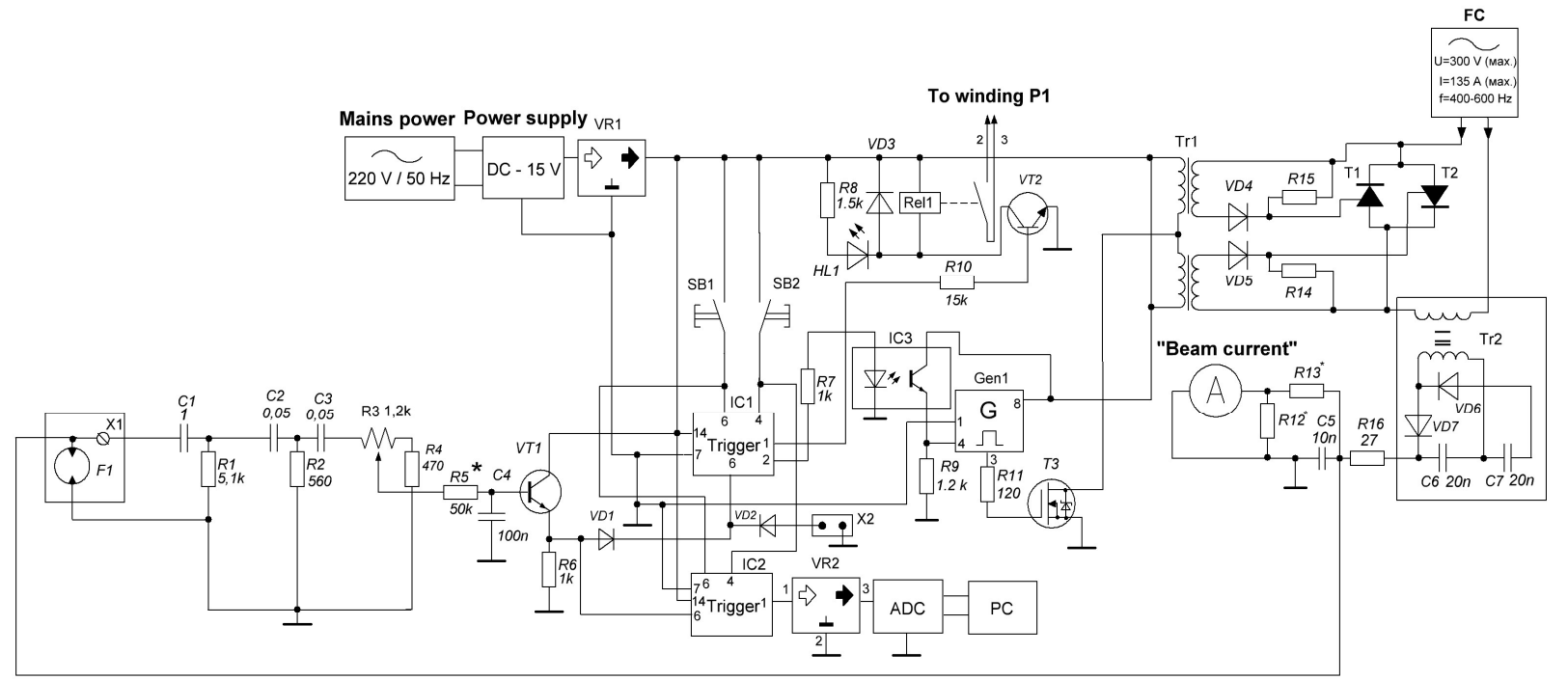

Fig. 3. Simplified schematic circuit diagram of the fast protection

To better understand the pulse generation principle, consider the principle of the generator "Gen1" main element operation - integrated chip (IC) NE555N [6]. The equivalent circuit of the NE555N IC is presented in Fig. 4. The NE555N chip generates a sequence of rectangular pulses, which frequency is determined by the $\mathrm{RC}$ circuit. In the initial state, the capacitor $\mathrm{C} 1$ is discharged, and the voltage level is close to zero at the inputs of both comparators. The comparator 2 switches the internal trigger and, as a consequence, a high level of potential is set at the chip output 3 . The transistor VT1 is closed and the capacitor C1 begins to charge up to $12 \mathrm{~V}$ through resistors $\mathrm{R} 1$ and $\mathrm{R} 2$.

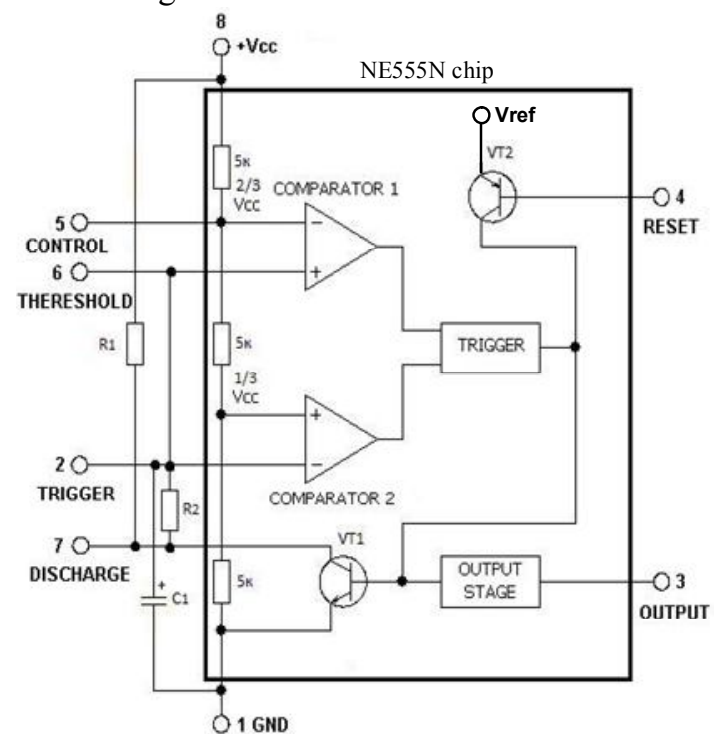

Fig. 4. The circuit "Gen1" made on the chip NE555N

When as a result of charging the voltage on the capacitor reaches $2 / 3$ of the supply voltage, the comparator 1 switches the trigger, which in turn sets a low potential level at the chip output 3 . The transistor VT1 is opened, and the capacitor $\mathrm{C} 1$ starts discharging through the resistor R2. As soon as the voltage on the capacitor reaches $1 / 3$ of the supply voltage, the comparator 2 switches the trigger again, and the chip output 3 will have a high voltage level again. The transistor VT1 is closed, and the capacitor $\mathrm{C} 1$ starts charging again. Thus, the circuit goes into periodic mode, and the voltage on the capacitor varies between the values of $1 / 3$ and $2 / 3$ of the supply voltage.

Express the capacitor $C_{1}$ charge time $t_{1}$ from the power supply from the voltage $(1 / 3) \cdot V_{c c}$ to $(2 / 3) \cdot V_{c c}$ in terms of resistors $R_{1}, R_{2}$ :

$$
\begin{gathered}
(2 / 3) \cdot V_{c c}=(1 / 3) \cdot V_{c c}+\left(V_{c c}-(1 / 3) \cdot V_{c c}\right) \times \\
\times\left(1-\exp \left(-t_{1} /\left(\left(R_{1}+R_{2}\right) \cdot \mathrm{C}_{1}\right)\right)\right) ; \\
t_{1}=-\ln (1 / 2) \cdot\left(R_{1}+R_{2}\right) \cdot C_{1}=\ln (2) \cdot\left(R_{1}+R_{2}\right) \cdot \mathrm{C}_{1} .
\end{gathered}
$$

Express the capacitor $C_{1}$ discharge time $t_{2}$ from the voltage $(2 / 3) \cdot V_{c c}$ to the voltage $(1 / 3) \cdot V_{c c}$ in terms of the resistor $R_{2}$ :

$$
\begin{aligned}
(1 / 3) \cdot & V_{c c}=(2 / 3) \cdot V_{c c}+\left(0-(2 / 3) \cdot V_{c c}\right) \times \\
& \times\left(1-\exp \left(-t_{2} /\left(R_{2} \cdot C_{1}\right)\right)\right) ; \\
t_{2}= & -\ln (1 / 2) \cdot R_{2} \cdot C_{1}=\ln (2) \cdot R_{2} \cdot C_{1} .
\end{aligned}
$$

In our case $\left(R_{1}=10 \mathrm{k} \Omega ; R_{2}=31 \mathrm{k} \Omega ; C_{1}=1 \mathrm{nF}\right)$, the pulse durations calculated by formulas (1) and (2) were: $t_{1}=2.829 \cdot 10^{-5} \mathrm{~s}, t_{2}=2.139 \cdot 10^{-5} \mathrm{~s}$. One complete cycle duration was $T=t_{1}+t_{2}=4.968 \cdot 10^{-5} \mathrm{~s}$, which corresponds to the signal frequency $f=T^{-1} \approx 20 \mathrm{kHz}$. Generically:

$$
f=T^{-1}=\left(\ln (2) \cdot\left(R_{1}+2 R_{2}\right) \cdot C_{1}\right)^{-1} .
$$

The pulse ratio in our case was:

$$
\begin{gathered}
S=T / t_{1}=1 / D=\left(t_{1}+t_{2}\right) / t_{1}= \\
=\left(R_{1}+2 R_{2}\right) /\left(R_{1}+R_{2}\right)=1.75 .
\end{gathered}
$$

A Duty Cycle was:

$$
D=t_{1} / T=1 / S=\left(R_{1}+R_{2}\right) /\left(R_{1}+2 R_{2}\right)=0.57=57 \% \text {. }
$$

The assurance of the above pulse parameters estimates at the NE555N chip output was experimentally confirmed by taking the oscillogram from output 3 of the "Gen1" chip (Fig. 5).

A generation failure is realized as follows: at the moment, when there is no breakdown in the gaseous medium, the chip IC1 output 6 doesn't receive any signal from breakdown sensor, and the first output has a logical value of " 0 ". At this time, the IC1 chip output 2 has a logic value "1", which corresponds to a voltage of $12 \mathrm{~V}$. This voltage leads to the IC3 chip operation, which thereafter leads to the opening of the IC1 chip bipolar transistor. At the moment of the transistor opening, the emitter current of the IC3 chip transistor creates the resistor $\mathrm{R} 9$ voltage drop, this voltage is applied to the generator "Gen1" chip output 4, which starts the generation of "Gen 1" pulses. 


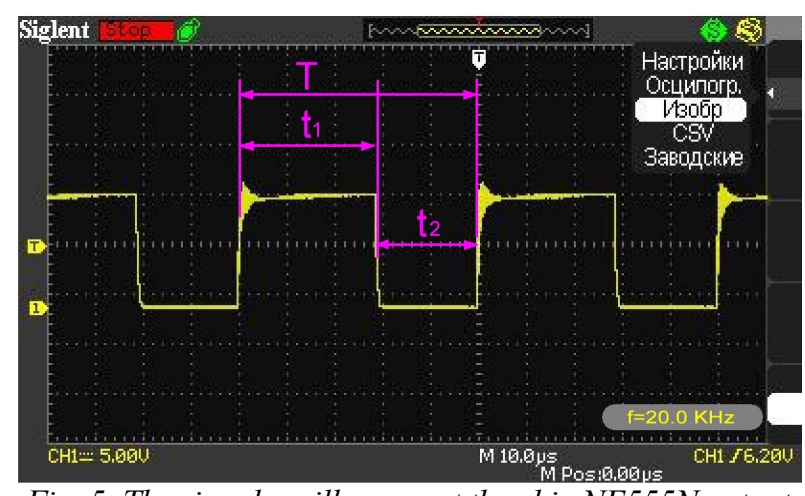

Fig. 5. The signal oscillogram at the chip NE555N output

When the IC1 chip output 6 receives a breakdown signal from the breakdown sensor, the logic values inverse change is occurred, and the trigger output 1 will have a logic value " 1 ", and the output 2 - logic value " 0 ", which corresponds to a voltage of $0 \mathrm{~V}$. It leads to the IC3 chip LED shutdown, the optical pair IC3 transistor closing. The voltage at output 4 of the generator "Gen 1" drops to zero, leading to a generation shutdown.

Another trigger IC2 on the CD4013 chip, which upon the signal receipt at its input (6 output of the chip), enters a stable operating state, and a logical value " 1 ", equivalent to $12 \mathrm{~V}$ appears at the output 1 , is simultaneously connected to the emitter of the transistor VT1. From the output of the trigger IC2 (output 1), the voltage is supplied to the chip VR2 of L7805 mark, which is an integrated voltage stabilizer (up to $5 \mathrm{~V}$ ). The voltage from the chip VR2 output 3 is supplied to an ADC/DAC module, which fixes the breakdown moment at its input voltage of $5 \mathrm{~V}$ from the VR2 chip. From the digital output of the chip, the signal arrives at the PC, and an error sign appears on the monitor, indicating a highvoltage breakdown. In the absence of breakdown at the IC 2 chip output 1 there is a logical value " 0 ", respectively, at the VR2 chip output 3 , the voltage will be $0 \mathrm{~V}$. The main element of the ADC/DAC module is an 8-bit Atmega 2560-16AU microcontroller.

To start the generator "Gen1" operation after the breakdown fixing and restore the possibility of power supply to the accelerator primary winding, it is necessary to reset the logic values of the triggers IC1, IC2 with one parallel connected button SB2. After pressing the button, the pulse generation of the "Gen1" generator resumes, and the error sign indicating a high-voltage breakdown on the PC monitor will disappear. The SB1 button is intended for control check of protection system operation. By its pressing, both triggers kick in, generation shutdown happens. The HL1 LED lights up, and an error sign appears on the PC monitor to indicate a breakdown.

When there are no breakdowns, the rectangular pulse signal is fed from the generator "Gen 1" output 3 through the resistor R11 to IRFZ44N series field-effect transistor T3. The transistor is loaded by the pulse transformer $\operatorname{Tr} 1$, which plays the role of galvanic isolation between power and control parts of the circuit. Next, through the primary winding, rectangular pulses are induced into the secondary winding of the transformer $\operatorname{Tr} 1$.

The primary and secondary windings of the transformer Tr1 have been wound by SEW-2 wire with $\varnothing 0.25 \mathrm{~mm}$. The primary winding consists of two ones connected in parallel, which contain the number of turns
$W_{1}=250$ each. The secondary winding consists of two independent windings with the number of turns $W_{2}=250$. The primary winding resistance is $10.5 \Omega$, the secondary $-9 \Omega$. The windings have been wound on a cylindrical plastic frame, on which two ferrite rings are installed. It should be noted that at present a perspective work is underway to substitute this transformer for seven-sided opto-drivers of the MOC series in order to increase ergonomics, compactness and facilitate system repair.

Impulses arrive from the secondary winding of the transformer Tr1 through the diodes VD3...VD6 to the thyristors T1, T2 of T-15-160-11 series. In case of high-voltage breakdowns, the thyristors "are closed" and stop the power supply to the transformer Tr2 primary winding (see Fig. 1,a) from the transistor frequency converter FC (see Fig. 3) of "APCH-TOP-40165/220-400-100-UHL4" mark. As a result, the accelerator is turned off in a time $\tau \approx 1.25 \cdot 10^{-3} \mathrm{~s}$ at a supply frequency of the accelerator primary winding of $400 \mathrm{~Hz}$.

The additional connection of other accelerator protection systems is carried out through the connector X2, from which the signal is fed to the trigger IC1, that triggers the protection system. The diodes VD1, VD2 allow to connect to the input X2 other protection systems of the accelerator for fast power off in the case, when other malfunctions appear. Nowadays, this has allowed us to connect "Protection system against burning-out of an outlet window foil" [7], developed by us, to the fast protection system.

The protection system efficiency test has been carried out in atmospheric conditions at different seasons by applying an increasing voltage to the high-voltage generator until the air insulation electrical breakdown fixing (Fig. 6). This allowed us to find out that the most frequently high-voltage breakdown in atmospheric conditions occurred at a voltage of $U=140 \ldots 200 \mathrm{kV}$ (ELV-1) and $U=200 \ldots 280 \mathrm{kV}($ ELV-2). Such a wide spread of breakdown voltages can be related to changes in atmospheric humidity in the air.

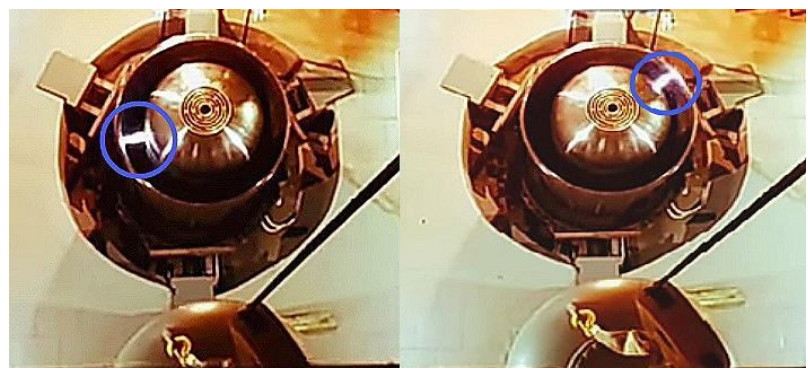

Fig. 6. High-voltage breakdown

Our research has shown that in the event of a gas electrical insulation emergency breakdown, the protection system, proposed by us, allows timely protecting the accelerator high-voltage rectifier from further operation in overload mode. The increase in system sensitivity enabled us to fix the moment of possible breakdown more accurately. Implemented technical possibility of the protection system connecting to the ADC/DAC module allowed controlling the system operating status by means a PC.

Well-timed protection system act significantly reduces the probability of accelerators prolonged emergency shutdowns. It is very important in production 
conditions in terms of costs associated with delays in making, as well as material costs related to accelerators repair.

The accelerators protection system, proposed by us, in the event of gas electrical insulation breakdown involves its use in a complex with other protection and control systems. This approach allows you to solve stepwise the problem of increasing the level of protection systems reliability for this series accelerators and control their operation.

\section{CONCLUSIONS}

As a result of the electron accelerators protection system improvement during high-voltage breakdown of gas electrical insulation, the following results have been obtained:

1. The system dimensions have been reduced due to blocking-generator removal and the implementation of an alternative generator on the integrated circuit. This allowed obtaining controlling rectangular pulses, which are more stable in frequency and pulse ratio.

2. The substitution of the bipolar power supply unit with different voltage values for the unipolar pulse power supply unit with a voltage of $12 \mathrm{~V}$ enabled us to simplify system maintenance and increased its reliability.

3. The protection system sensitivity has been increased due to the proposed sensor of gas electrical insulation high-voltage breakdown on a bipolar transistor and a trigger.

4. The use of the ADC/DAC module has provided the ability to connect additional sensors to monitor the occurrence of emergencies and allowed displaying information about accelerator operating status on the computer monitor for the plant operator.

\section{FURTHER PROSPECTS OF RESEARCH}

Further research in the area of improving the electron accelerators protection systems from emergencies and control for their operation can be aimed at: development of software and hardware for automatic control of accelerator physical processes; connection of the ADC/DAC module through the RS-485 interface via ModBUS RTU protocol to the transistor converter con- trol system by involving the UART TTL Module - RS485; improvement of other accelerator protection systems with the possibility to be integrated with the fast protection system, proposed by us.

\section{REFERENCES}

1. P.I. Nemytov. Sistemyi pitaniya i upravleniya serii vyisokovoltnyih promyishlennyih uskoriteley elektronov s moschnostyu vyivedennogo puchka sotni kilovatt: Diss. doct. tehn. nauk. Novosibirsk, 2010, p. 13-17 (in Russian).

2. N.K. Kuksanov, S.N. Fadeev, Yu.I. Golubenko, et al. Development of the model range and improve performance accelerators ELV // Problems of Atomic Science and Technology. Series "Nuclear Physics Investigations”. 2012, № 3, p. 15-18.

3. G.I. Budker, V.A. Gaponov, B.M. Korabelnikov, et al. Electron accelerator for industrial use // Atomnaja jenergija. 1976, v. 40, № 3, p. 216-219 (in Russian).

4. V.N. Zajczev, S.A. Kuzneczov, R.A. Salimov, S.N. Fadeev, V.G. Cherepkov. Istochnik pitaniya moshhnogo e lektronnogo uskoritelya: Preprint 9050. Institut yadernoj fiziki SO AN SSSR. Novosibirsk, 1990, p. 23-29 (in Russian).

5. Patent 131551 UA, MPK (2018.01) H05H 15/00 G21K 1/00. Sistema shvidkogo zahistu pri visokovoltnih proboyah dlya priskoryuvachiv elektroniv ELV-1, ELV-2 / S.O. Bandurov, u201806193; Zayav. 04.06.2018; Opubl. 25.01.2019, Byul, № 2 (in Ukrainian).

6. Datasheet (PDF) [Electronic resource] / National Semiconductor Corporation. LM 555 Timer, July 2006, p. 2. Access mode: https:/html.alldatasheet.com/ html-pdf/8982/NSC/LM555CMM/82/2/LM555CMM. html (Date of the application: 24.07.2020).

7. S.O. Bandurov, R.S. Lozhkin, G.O. Shishkin. Improved burning down protection system of industrial electron accelerators outlet window foil // Problems of Atomic Science and Technology. Series "Plasma Electronics and New Methods of Acceleration". 2019, № 4, p. 169-173.

Article received 21.09.2020

\section{УСОВЕРШЕНСТВОВАННАЯ СИСТЕМА БЫСТРОЙ ЗАЩИТЫ ПРИ ВЫСОКОВОЛЬТНЫХ ГАЗОВЫХ ПРОБОЯХ ДЛЯ ПРОМЫШЛЕННЫХ УСКОРИТЕЛЕЙ ЭЛЕКТРОНОВ}

\section{С.О. Бандуров, Р.С. Ложкин, Г.А. Шишкин}

Рассмотрены пути совершенствования системы защиты линейных ускорителей электронов серий ЭЛВ-1 и ЭЛВ-2 на основе современных интегральной и полупроводниковой компонентной баз. Предложенные схемотехнические решения позволили при пробоях газовой электрической изоляции в быстром режиме отключать питание установки, что делает невозможным ее работу в аварийном режиме. С целью повышения качества контроля за работой ускорителя и дополнительного информирования оператора в предложенной системе реализована возможность вывода информации на монитор компьютера оператора.

\section{ВДОСКОНАЛЕНА СИСТЕМА ШВИДКОГО ЗАХИСТУ ПРИ ВИСОКОВОЛЬТНИХ ГАЗОВИХ ПРОБОЯХ ДЛЯ ПРОМИСЛОВИХ ПРИСКОРЮВАЧІВ ЕЛЕКТРОНІВ}

\section{С.О. Бандуров, Р.С. Ложкін, Г.О. Шишкін}

Розглянуто шляхи вдосконалення системи захисту лінійних прискорювачів електронів серій ЕЛВ-1 та ЕЛВ-2 на основі сучасних інтегральної та напівпровідникової компонентної баз. Запропоновані схемотехнічні рішення дозволили при пробоях газової електричної ізоляції в швидкому режимі відключати живлення установки, що унеможливить їі роботу в аварійному стані. 3 метою підвищення якості контролю за роботою прискорювача та додаткового інформування оператора в запропонованій системі реалізована можливість виводу інформації на монітор комп’ютера оператора. 